\title{
Effect of ketamine on intravenous patient-controlled analgesia using hydromorphone and ketorolac after the Nuss surgery in pediatric patients
}

\author{
Too Jae Min, Woon Young Kim, Won Ju Jeong, Jae Ho Choi, Yoon Sook Lee, Jae Hwan Kim, and \\ Young Cheol Park
}

Department of Anesthesiology and Pain Medicine, Korea University Ansan Hospital, Ansan, Korea

Background: Nuss surgery is preferred in pectus excavatum repair because this procedure produces excellent cosmetic results and prevents postoperative distressed pulmonary function. However, the procedure causes severe pain due to thoracic expansion. This study was designed to investigate the analgesic effect of small doses of ketamine on an intravenous patient-controlled analgesia (IV-PCA) using hydromorphone and ketorolac for pain control after Nuss surgery.

Methods: Forty-four patients undergoing elective Nuss surgery were randomly assigned to receive hydromorphone 3 $\mu \mathrm{g} / \mathrm{kg} / \mathrm{hr}$, ketorolac $0.05 \mathrm{mg} / \mathrm{kg} / \mathrm{hr}$ and ondansetron $0.1 \mathrm{mg} / \mathrm{kg} /$ day (Group HO, $\mathrm{n}=22$ ) or hydromorphone $3 \mu \mathrm{g} / \mathrm{kg} /$ $\mathrm{hr}$, ketorolac $0.05 \mathrm{mg} / \mathrm{kg} / \mathrm{hr}$, ondansetron $0.1 \mathrm{mg} / \mathrm{kg} /$ day and ketamine $0.15 \mathrm{mg} / \mathrm{kg} / \mathrm{hr}$ (Group HK, $\mathrm{n}=22$ ) via an IVPCA pump after surgery. A blind observer evaluated each patient using the Modified Children's Hospital of Eastern Ontario Pain Scale (CHEOPS) for the assessment of pain control. The total administered PCA volume, side effects and parents satisfaction with pain control were assessed at postoperative 1, 4, 8, 12, 24, and 48 hours.

Results: There were no significant differences in Modified CHEOPS between the groups during postoperative 48 hours. The total PCA volume in group HK was significantly lower than that in group HO $(\mathrm{P}<0.05)$. The side effects in both groups did not significantly differ except for pruritus. The levels of satisfaction from the parents were not significantly different between the groups.

Conclusions: A small dose of ketamine on IV-PCA reduced the total administered dose of IV-PCA with hydromorphone and ketorolac and reduced the incidence of pruritus after the Nuss procedure in pediatric patients. (Korean J Anesthesiol 2012; 62: 142-147)

Key Words: Hydromorphone, Ketamine, Patient-controlled analgesia, Pectus excavatum.

Received: June 10, 2011. Revised: 1st, August 18, 2011; 2nd, September 19, 2011. Accepted: October 11, 2011.

Corresponding author: Woon Young Kim, M.D., Ph.D., Department of Anesthesiology and Pain Medicine, Korea University Ansan Hospital, 516, Gojan-dong, Ansan 425-707, Korea. Tel: 82-31-412-5291, Fax: 82-31-413-5294, E-mail: ckssis@korea.ac.kr

(c) This is an open-access article distributed under the terms of the Creative Commons Attribution Non-Commercial License (http:// creativecommons.org/licenses/by-nc/3.0/), which permits unrestricted non-commercial use, distribution, and reproduction in any medium, provided the original work is properly cited. 


\section{Introduction}

Pectus excavatum is a congenital deformity in which the sternum and the inferior costal cartilage area are depressed. This condition appears at birth and gradually progresses, developing to the menubrial area. The most severe depression occurs in the xiphoid process, and the incidence has been reported to be $0.01-0.1 \%$ [1]. In 1998, Nuss et al. [2] reported on a method that shows excellent esthetic results and improves the deterioration of lung function through the use of specially made metal rods fitted to the chest deformity of a patient. However, such surgical methods can induce severe postsurgical pain in pediatric patients due to expansion of the thorax. The pain can be controlled through the injection of narcotic analgesics or the injection of non-narcotic analgesics into the epidural space [3] or intramuscularly $[4,5]$. In children, injection through the epidural space is inappropriate, and major complications can occur [3,6]. Intravenous patient-controlled analgesia (IV-PCA) may be preferred by patients over intramuscular injection due to the lack of anxiety-induced pain with IV-PCA compared to that resulting from intramuscular injections [5].

Hydromorphone is a semi-synthetic opioid in which the hydroxyl group of morphine is substituted with oxygen and the double bond of 7-8 position is hydrogenated. Its lipid solubility is slightly higher than that of morphine, and the maintenance period is 3-5 hours, which is slightly shorter than that of morphine [7]. Hydromorphone has commonly been viewed as a second-line drug to morphine in the treatment of both acute and chronic pain [8].

Ketorolac is an effective drug with an analgesic potency comparable to that of opioids. Its mechanism of action is the suppression of prostaglandin synthesis unrelated to opioid agents, and thus the use of ketorolac may facilitate return of gastrointestinal function, reduce nausea, decrease respiratory depression, and improve patient satisfaction [9]. When ketorolac is used in combination with opioid agents, it exerts opioidsparing effects and improves analgesic action, and it is also used frequently in combination with opioid analgesics in IV-PCA [10-12]. Studies on the combined administration of hydromorphone and ketorolac have not previously been conducted. Therefore, in this study, by referring to the results of the supplemental administration of ketorolac from several previous studies [9-12], hydromorphone and ketorolac were added to the basic IV-PCA.

It has been reported that the antagonist of the NMDA receptor, ketamine, reduces pain by suppressing the sensitization of the central nervous system and the development of opioid resistance [13,14]. Nesher et al. [15] and Kollender et al. [16] have reported that the additional injection of a small dose of ketamine resulted in a $50-60 \%$ reduction in the dose of morphine used in IV-PCA, and side effects such as nausea and vomiting were diminished. In addition, the need for supplemental analgesics was reduced. Studies on the effect of ketamine administered in combination with morphine have been reported; however, the effect of ketamine combined with hydromorphone and ketorolac on IV-PCA has not been examined.

Therefore, the present study was undertaken to investgate the analgesic effect and side effects of co-administered small dose of ketamine on IV-PCA using hydromorphone and ketorolac for pain control after Nuss surgery.

\section{Materials and Methods}

Among the 3-13-year-old pediatric patients scheduled for Nuss surgery at our institution, 44 patients (American Society of Anesthesiologists physical status I-II) were recruited for participation in this study. After obtaining approval from the hospital ethics committee, the subjects were divided randomly into two groups: the HO group was administered $3 \mu \mathrm{g} / \mathrm{kg} / \mathrm{hr}$ hydromorphone, $0.05 \mathrm{mg} / \mathrm{kg} / \mathrm{hr}$ ketorolac, and $0.1 \mathrm{mg} / \mathrm{kg} /$ day ondansetron, and the HK groups was additionally administered $0.15 \mathrm{mg} / \mathrm{kg} / \mathrm{hr}$ ketamine. The anesthesiologist providing anesthesia and observers participating in the pain and side effects assessments were unaware of the type of medication administered. All patients and parents were also blinded to their group assignment. There were 22 patients in each group, consent for pain control was obtained from parents, and the equipment and procedure were explained in detail. Patients with cardiac anomaly, Marfan syndrome, and other underlying cardiac diseases, patients with history of severe side effects after the use of opioid analgesics, patients with a history of psychiatric diseases, and cases of contraindication for the drugs used in our experiment were excluded.

Atropine $0.01 \mathrm{mg} / \mathrm{kg}$ as premedication was injected intramuscularly 30 mins -1 hour before the induction of anesthesia. Blood pressure, pulse rate and peripheral oxygen saturation were measured prior to and during surgery. Thiopental sodium $5 \mathrm{mg} / \mathrm{kg}$, and rocuronium $0.6 \mathrm{mg} / \mathrm{kg}$ were administered intravenously and the endotracheal intubation was then performed. Anesthesia was maintained with oxygen $1 \mathrm{~L} / \mathrm{min}$, air $1.5 \mathrm{~L} / \mathrm{min}$ and sevoflurane at $4-6$ vol\%, while controlled ventilation was performed to sustain end-tidal carbon dioxide $\left(\mathrm{ETCO}_{2}\right)$ between 30 and $35 \mathrm{mmHg}$. Immediately prior to the incision of the skin, a bolus of $5 \mu \mathrm{g} / \mathrm{kg}$ hydromorphone and 0.1 $\mathrm{mg} / \mathrm{kg}$ ondansetron were injected for preemptive analgesic effect and for the prevention of movement and instability of vital signs due to severe pain. Hydromorphone $3 \mu \mathrm{g} / \mathrm{kg} / \mathrm{hr}$, ketorolac $0.05 \mathrm{mg} / \mathrm{kg} / \mathrm{hr}$ and ondansetron $0.1 \mathrm{mg} / \mathrm{kg} /$ day in group $\mathrm{HO}$ and hydromorphone $3 \mu \mathrm{g} / \mathrm{kg} / \mathrm{hr}$, ketorolac $0.05 \mathrm{mg} /$ $\mathrm{kg} / \mathrm{hr}$, ondansetron $0.1 \mathrm{mg} / \mathrm{kg} /$ day and additional ketamine 
$0.15 \mathrm{mg} / \mathrm{kg} / \mathrm{hr}$ in group HK were started via an IV-PCA pump after a bolus injection of $5 \mu \mathrm{g} / \mathrm{kg}$ hydromorphone and $0.1 \mathrm{mg} /$ $\mathrm{kg}$ ondansetron. The total dose of drugs was determined to be $72 \mathrm{ml}$ and the infusion rate, bolus dose and lock out time were set at $1 \mathrm{ml} / \mathrm{hr}, 0.5 \mathrm{ml}$, and $30 \mathrm{~min}$ respectively. The level of pain was measured at 1, 4, 8, 12, 24, and 48 hours after surgery according to the Modified CHEOPS [17] (Table 1) by a resident anesthesiologist.

In addition, while assessing the level of pain, the satisfaction levels of patients were divided into four levels: very satisfied (4); generally satisfied (3); moderately satisfied (2); and unsatisfied (1). Satisfaction levels were recorded at 12, 24, and 48 hours after surgery based on verbal responses from the patients or parents. The delirium score and sedation scale after surgery were observed 1 hour after surgery. The delirium scores were divided into four levels: sleeping (1); awake but quiet (2); excited but able to be calmed (3); and very excited and thus difficult to calm (4). The sedation scale were classified as: alert condition (0); occasionally sleepy but able to answer questions (1); frequently sleepy but able to answer questions (2); responded to physical stimulation (3); and sleeping continuously without responding to physical stimulation (4). In addition, the nausea scale was recorded as none (1); dry heave (2); vomited once (3); and vomited several times (4). The side effects such as pruritus, hypoventilation, constipation, headache, dizziness, delirium, nightmare, and hallucination were assessed. For patients who presented with pain higher than a rating of 4 on the Modified CHEOPS, $0.5 \mathrm{mg} / \mathrm{kg}$ ketorolac was administered and recorded. For patients who vomited more than two times, $0.1 \mathrm{mg} / \mathrm{kg}$

Table 1. Modified CHEOPS (Children's Hospital of Eastern Ontario Pain Scale)

\begin{tabular}{llll}
\hline Score & \multicolumn{1}{c}{0} & \multicolumn{1}{c}{1} & \multicolumn{1}{c}{2} \\
\hline Cry & No cry & Crying, moaning & Scream \\
Facial & Smiling & Composed & Grimace \\
Verbal & Positive & None or other complaints & Pain complaint \\
Torso & Neutral & Shifting, tense, upright & Restrained \\
Legs & Neutral & Kicks, squirm, drawn up & Restrained \\
Touch & Not touching & Reach, touch, grab & Restrained \\
\hline
\end{tabular}

Table 2. Demographic Characteristics

\begin{tabular}{lcc}
\hline & $\begin{array}{c}\text { Group HO } \\
(\mathrm{n}=22)\end{array}$ & $\begin{array}{c}\text { Group HK } \\
(\mathrm{n}=22)\end{array}$ \\
\hline Age (yr) & $8.4 \pm 6.6$ & $7.3 \pm 3.9$ \\
Weight (kg) & $25.8 \pm 10.4$ & $27.6 \pm 14.0$ \\
Height (cm) & $124.9 \pm 22.3$ & $124.7 \pm 26.4$ \\
Sex (M/F) & $14 / 8$ & $16 / 6$ \\
\hline
\end{tabular}

Values are expressed as mean \pm SD or patient numbers. Group HO: hydromorphone $3 \mu \mathrm{g} / \mathrm{kg} / \mathrm{hr}$, ketorolac $0.05 \mathrm{mg} / \mathrm{kg} / \mathrm{hr}$, ondansetron $0.1 \mathrm{mg} / \mathrm{kg} /$ day. Group HK: hydromorphone $3 \mu \mathrm{g} / \mathrm{kg} / \mathrm{hr}$, ketorolac 0.05 $\mathrm{mg} / \mathrm{kg} / \mathrm{hr}$, ondansetron $0.1 \mathrm{mg} / \mathrm{kg} /$ day and ketamine $0.15 \mathrm{mg} / \mathrm{kg} / \mathrm{hr}$. ondansetron was administered and recorded. In addition, for observation of recovery of digestive system function, the time of the first gas release after surgery and the time of defecation were recorded.

Based on a previous studies $[15,18,19]$, this study was powered to detect such a reduction with type 1 error of 0.05 (two tailed) and desired power of 0.8. Based on these assumptions, 20 patients per group were required. We planned to enroll enough patients to obtain 22 patients per group. All measured values in this study are presented as a mean \pm standard deviation and are described as the percentage of total patients. For statistical analysis, SPSS version 12.0 (SPSS Inc. Chicago, USA) was used. For the differences in age, height and weight between the groups, the Mann-Whitney test was applied. The differences in gender, side effects, and the additional administration of analgesics and antiemetics in the groups were analyzed using Fisher's exact test. For comparison of the groups of the time points within a group, repeated measures of ANOVA were conducted, and followed by the post-hoc analysis method Bonferroni test. $\mathrm{P}$ values less than 0.05 were considered statistically significant.

\section{Results}

The ages, genders, weights and heights of the two groups did not show significant differences (Table 2). The Modified CHEOPS pain scores of the HO and HK groups after 1, 4, 8, 12, 24 , and 48 hours did not significantly differ (Fig. 1). The total administered volume via IV-PCA was significantly reduced in

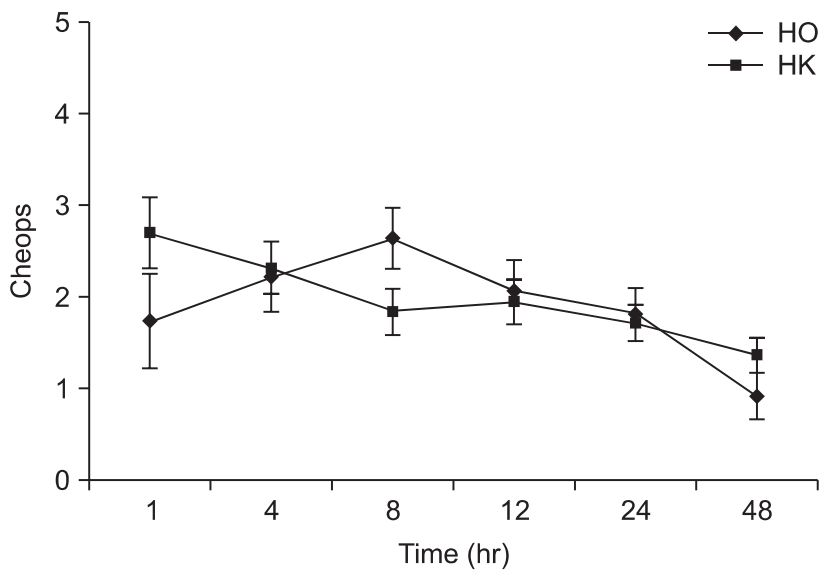

Fig. 1. Changes of postoperative pain score using Children's Hospital of Eastern Ontario Pain Scale (CHEOPS) during $48 \mathrm{hr}$ after emergence in intravenous patient controlled analgesia (IV-PCA) groups. Data are represented as mean \pm SD. There were no statistical differences between the groups with regards to the CHEOPS at 0.05 levels. HO: hydromorphone + ketorolac group, HK: hydromorphone + ketorolac + ketamine group. 
Table 3. Change of Total Infused IV-PCA Volume (ml)

\begin{tabular}{lcccccc}
\hline \multicolumn{1}{c}{ Time (h) } & 1 & 4 & 8 & 12 & 24 & 48 \\
\hline IV-PCA volume (ml) & & & & & \\
HO & $3.3 \pm 0.3$ & $7.7 \pm 0.4$ & $13.0 \pm 0.6$ & $16.9 \pm 0.7$ & $30.8 \pm 0.8$ & $57.8 \pm 2.5$ \\
HK & $3.2 \pm 0.2$ & $7.4 \pm 0.3$ & $10.8 \pm 0.4^{*}$ & $15.3 \pm 0.5$ & $27.7 \pm 0.6^{*}$ & $50.8 \pm 1.9 *$ \\
\hline
\end{tabular}

Values are expressed as mean \pm SD. Group HO: hydromorphone $3 \mu \mathrm{g} / \mathrm{kg} / \mathrm{hr}$, ketorolac $0.05 \mathrm{mg} / \mathrm{kg} / \mathrm{hr}$, ondansetron $0.1 \mathrm{mg} / \mathrm{kg} / \mathrm{day}$. Group HK: hydromorphone $3 \mu \mathrm{g} / \mathrm{kg} / \mathrm{hr}$, ketorolac $0.05 \mathrm{mg} / \mathrm{kg} / \mathrm{hr}$, ondansetron $0.1 \mathrm{mg} / \mathrm{kg} /$ day and ketamine $0.15 \mathrm{mg} / \mathrm{kg} / \mathrm{hr}$. *P $<0.05$ compared with group HO.

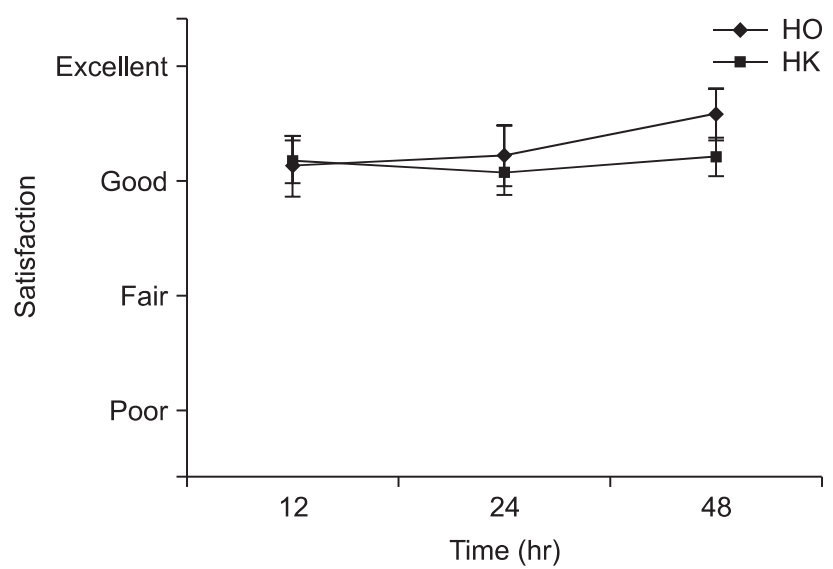

Fig. 2. Satisfaction of pain control was assessed by parents at postoperative 12, 24 and $48 \mathrm{hrs}$ and expressed as excellent, good, fair and poor. There were no statistical differences between the groups with regards to satisfaction at 0.05 levels. But the parents of both groups were generally satisfied with pain control. HO: hydromorphone + ketorolac group, HK: hydromorphone + ketorolac + ketamine group.

the HK group compared to that in the HO group at 8, 24 and 48 hours after the completion of surgery (Table 3 ). The satisfaction levels of patients or parents were not significantly different between the two groups (Fig. 2).

The delirium scores of the HO group and the HK group were $1.3 \pm 0.5$ and $1.5 \pm 0.6$ and the sedation scores were $0.7 \pm 1.0$ and $1.0 \pm 1.1$, respectively; no differences were detected between the two groups. Hypoventilation, dizziness, abdominal pain, the time of gas release, and defection time did not show differences between the groups. The score of nausea and vomiting and the number of antiemetic drug injections were also not different, nor was the additional administration of analgesics. Nevertheless, pruritus was observed more frequently in the $\mathrm{HO}$ group than in the HK group (Table 4).

\section{Discussion}

Nuss surgery is a minimally invasive procedure; however, postsurgical pain is a major problem associated with this technique [2]. To prevent postsurgical lung complications or the displacement of the metal rod, bed rest after pectus excavatum surgery is crucial [6]. In addition, the forceful movement of the
Table 4. Postoperative Effects of Test Drug Treatments

\begin{tabular}{lcc}
\hline & $\begin{array}{c}\text { Group HO } \\
(\mathrm{n}=22)\end{array}$ & $\begin{array}{c}\text { Group HK } \\
(\mathrm{n}=22)\end{array}$ \\
\hline Delirium scale & $1.3 \pm 0.5$ & $1.5 \pm 0.6$ \\
Sedation scale & $0.7 \pm 1.0$ & $1.0 \pm 1.1$ \\
Nausea scale & $2.1 \pm 0.8$ & $2.4 \pm 1.2$ \\
Anti-emetics & $7 / 22(32 \%)$ & $9 / 22(41 \%)$ \\
Abdominal pain & $6 / 22(27 \%)$ & $5 / 22(23 \%)$ \\
Gas-out time (hr) & $26.5 \pm 12.2$ & $32.2 \pm 16.1$ \\
Defecation time (hr) & $75.2 \pm 23.3$ & $69.2 \pm 25.9$ \\
Pruritus & $7 / 22(32 \%)$ & $1 / 22(5 \%) *$ \\
Dizziness & $1 / 22(5 \%)$ & $2 / 22(9 \%)$ \\
Dyspnea & $0 / 22(0 \%)$ & $1 / 22(5 \%)$ \\
Painkiller injection & $12 / 22(55 \%)$ & $13 / 22(59 \%)$ \\
\hline
\end{tabular}

Values are expressed as mean \pm SD or absolute numbers of the group numbers and as a percentage. Group HO: hydromorphone $3 \mu \mathrm{g} / \mathrm{kg} /$ hr, ketorolac $0.05 \mathrm{mg} / \mathrm{kg} / \mathrm{hr}$, ondansetron $0.1 \mathrm{mg} / \mathrm{kg} /$ day. Group HK: hydromorphone $3 \mu \mathrm{g} / \mathrm{kg} / \mathrm{hr}$, ketorolac $0.05 \mathrm{mg} / \mathrm{kg} / \mathrm{hr}$, ondansetron $0.1 \mathrm{mg} / \mathrm{kg} /$ day and ketamine $0.15 \mathrm{mg} / \mathrm{kg} / \mathrm{hr}$. ${ }^{*} \mathrm{P}<0.05$ compared with group $\mathrm{HO}$.

sternum causes substantial pain in the chest and back of the patient. Since the chest and back correspond to the dermatomes in a wide area from the $1-10$ thoracic vertebrae, pain is difficult to control [20]. Thoracic epidural block is an effective method for pain control; however, because surgery subjects are often children, the technique is difficult. It is also complicated to maintain catheters, and hypotension may develop after the procedure [20]. Therefore, IV-PCA is considered to be the most effective pain control method after Nuss surgery.

Major drugs used for IV-PCA are morphine, hydromorphone, meperidine, fentanyl and other opioid analgesics, often used in combination with a non-steroid anti-inflammatory drug (NSAID) [9]. In performing PCA, the side effects of opioid analgesics such as hypoventilation, drowsiness, nausea, vomiting, and pruritus act as limiting factors. Numerous studies have been conducted to obtain effective analgesic effects while reducing such side effects [8-10,12,21].

Even though hydromorphone is a potent analgesic for the management of acute and chronic pain, it is the second drug of choice after morphine. The onset time of hydromorphone is within 5 minutes, which is slightly faster than that of morphine and the maximum effect is between 10 and 20 minutes [7]. The maintenance period is $3-5$ hours, which is slightly shorter than 
that of morphine [7]. The equianalgesic ratio for parenteral morphine to parenteral hydromorphone is $5: 1-7: 1$ [8]. Chang et al. [22] reported that there is little difference between morphine and hydromorphone in terms of analgesic efficacy and similar side effects except pruritus. Rapp et al. [21] reported that the levels of pain control were achieved by these two drugs and side effects were similar between two drugs, while hydromorphone improves the moods of patients and morphine caused less cognitive impairment. Therefore, hydromporphone is a suitable alternative to morphine.

Ketorolac administered in our study is a powerful drug with an analgesic potency similar to those of opioid drugs, and it is frequently administered in combination with opioid analgesics [9]. Picard et al. [11] have reported that the co-administration of morphine and ketorolac results in superior analgesic effects by up to to 2.6 times compared with those of the drugs administered alone. In addition, Kim et al. [12] reported that the addition of ketorolac to fentanyl resulted in the same analgesic efficacy but less nausea, vomiting and drowsiness. Studies on the combined administration of hydromorphone and ketorolac have not previously been conducted. In this study, by referring to the results of the supplemental administration of ketorolac from several previous studies [9-12], hydromorphone and ketorolac were added to the basic IV-PCA.

The administration of a small dose of ketamine is defined as a single injection of less than $1 \mathrm{mg} / \mathrm{kg}$ or continuous injection of less than $0.1-0.2 \mathrm{mg} / \mathrm{kg} / \mathrm{hr}$ for pain management [23]. It is controversial whether the simultaneous injection of a small amount of ketamine and opioid analgesics reduces the dose of opioid analgesics needed immediately after surgery and afterward [14-16,24]. Nesher et al. [15] have reported that in patients who underwent open chest surgery, in contrast to those given only morphine, the dose of morphine was reduced by approximately $50 \%$ in the group injected with simultaneous ketamine and morphine. In addition, the pain score and postsurgical nausea and vomiting were reduced, and the frequency of additional analgesics was reduced by half. Kollender et al. [16] have reported that the addition of ketamine to morphine allowed the dose of morphine to be reduced by $60 \%$, and lower and more stable pain scores and a shorter time of IV-PCA application were observed. In our study, the total dose of hydromorphone and ketorolac was reduced by approximately $13 \%$. Although this reduction level was different, the results appear to be in agreement with previous other studies. It is thought that the discrepancy in results was due to the additional injection of ketorolac and the onset time of the effect of hydromorphone was shorter compared with morphine, thus the necessity of additional administration of analgesics to reach the required effective dose was decreased. Urban et al. [18] have reported that postsurgical pain scores were reduced when ketamine was co-injected with hydromorphone in continuous IV-PCA. Total amount of hydromorphone used during postoperative 48 hours was reduced by $25 \%$. However, this was not significant because of the large standard deviation.

In our study, the incidences of side effects did not show differences in the two groups except for pruritus. Additionally, the unpleasant feelings or confusion that may be induced by ketamine were not observed, and hypoventilation did not develop. The nausea and vomiting scores of the two groups were not different, which contradicts the results of previous studies that found the combined administration of morphine and ketamine resulted in a reduced incidence of nausea [16,25]. This discrepancy is thought to be due to other factors such as relatively fewer side effects of hydromorphone in comparison with those of morphine, the combined administration with ketorolac, the anesthetic method, and the surgical method (Nuss procedure). In regard to pruritus, the incidences in the HO group and the HK group were $7 / 22$ (32\%) and 1/22 (5\%), respectively, and it was approximately seven times more prevalent in the HO group. Javery et al. [25] and Murdoch et al. [26] have also reported the reduction of pruritus in the group receiving additional ketamine. Such effects of ketamine have been reported to be due to the suppression of the central sensitization and reduced tolerance to opioid analgesics.

To conduct studies on the addition of a small dose of ketamine as a continuum of the prior studies is thought to be a superior investigation method. Therefore, we believe that the study on the effect of additional ketorolac on hydromorphone in IV-PCA after Nuss surgery must preced before this study and this is the limitation of this study. Nevertheless, previous studies have shown that combination treatment with ketorolac improved the analgesic effects of opioid analgesics and reduced the total dose in comparison with those of the treatment with opioid analgesics alone [10,11]. In consideration of the ethical issues of the dose of opioid analgesics administered to the control group patients as well as in consideration of the clinical effects on pain control after the combination administration of hydromorphone with ketorolac, the effect of a small amount of ketamine on pain was examined. For the control of acute pain in patients, the administration of additional drugs in multistep methods may be ineffective for pain control. If pain is not treated at the appropriate times, injury to nociceptive nerves and central sensitization may be induced, leading to allodynia and hyperpathia. Hence, Good et al. [27] suggested triple-agent therapy involving the co-injection of opioid analgesics, NSAIDs, and ketamine in the early period. This is similar to our method for patients undergoing Nuss surgery, a procedure which induces severe post-operative pain.

In conclusion, the administration of IV-PCA with hydromorphone, ketorolac, and a small dose of ketamine resulted in 
a reduction of the total administered dose of hydromorphone and ketorolacand the incidence of pruritus was significantly reduced without increasing other side effects. Therefore, if IVPCA is used for effective pain control after Nuss surgery for the correction of pectus excavatum in children, the combination of a small amount of ketamine with hydromorphone and ketorolac is recommended.

\section{References}

1. de Matos AC, Bernardo JE, Fernandes LE, Antunes MJ. Surgery of chest wall deformities. Eur J Cardiothorac Surg 1997; 12: 345-50.

2. Nuss D, Kelly RE Jr, Croitoru DP, Katz ME. A 10-year review of a minimally invasive technique for the correction of pectus excavatum. J Pediatr Surg 1998; 33: 545-52.

3. McBride WJ, Dicker R, Abajian JC, Vane DW. Continuous thoracic epidural infusions for postoperative analgesia after pectus deformity repair. J Pediatr Surg 1996; 31: 105-7.

4. Quigley C, Wiffen P. A systematic review of hydromorphone in acute and chronic pain. J Pain Symptom Manage 2003; 25: 169-78.

5. Urquhart ML, Klapp K, White PF. Patient-controlled analgesia: a comparison of intravenous versus subcutaneous hydromorphone. Anesthesiology 1988; 69: 428-32.

6. Futagawa K, Suwa I, Okuda T, Kamamoto H, Sugiura J, Kajikawa $\mathrm{R}$, et al. Anesthetic management for the minimally invasive Nuss procedure in 21 patients with pectus excavatum. J Anesth 2006; 20: 48-50.

7. Coda B, Tanaka A, Jacobson RC, Donaldson G, Chapman CR. Hydromorphone analgesia after intravenous bolus administration. Pain 1997; 71: 41-8.

8. Quigley C. Hydromorphone for acute and chronic pain. Cochrane Database Syst Rev 2002: (1): CD003447.

9. Christopher LW. Acute postoperative pain. In: Miller's Anesthesia, 6th ed. Edited by Miller RD: Philadelphia, Elsevier Churchill Livingstone. 2005, pp 2729-62.

10. Chen JY, Wu GJ, Mok MS, Chou YH, Sun WZ, Chen PL, et al. Effect of adding ketorolac to intravenous morphine patient-controlled analgesia on bowel function in colorectal surgery patients-a prospective, randomized, double-blind study. Acta Anaesthesiol Scand 2005; 49: 546-51.

11. Picard P, Bazin JE, Conio N, Ruiz F, Schoeffler P. Ketorolac potentiates morphine in postoperative patient-controlled analgesia. Pain 1997; 73: 401-6.

12. Kim SY, Kim EM, Nam KH, Chang DJ, Nam SH, Kim KJ. Postoperative intravenous patient-controlled analgesia in thyroid surgery: comparison of fentanyl and ondansetron regimens with and without the nonsteroidal anti-inflammatory drug ketorolac. Thyroid 2008; 18: 1285-90.

13. Woolf CJ, Thompson SW. The induction and maintenance of central sensitization is dependent on N-methyl-D-aspartic acid receptor activation; implications for the treatment of post-injury pain hypersensitivity states. Pain 1991; 44: 293-9.

14. Subramaniam K, Subramaniam B, Steinbrook RA. Ketamine as adjuvant analgesic to opioids: a quantitative and qualitative systematic review. Anesth Analg 2004; 99: 482-95.

15. Nesher N, Serovian I, Marouani N, Chazan S, Weinbroum AA. Ketamine spares morphine consumption after transthoracic lung and heart surgery without adverse hemodynamic effects. Pharmacol Res 2008; 58: 38-44.

16. Kollender Y, Bickels J, Stocki D, Maruoani N, Chazan S, Nirkin A, et al. Subanaesthetic ketamine spares postoperative morphine and controls pain better than standard morphine does alone in orthopaedic-oncological patients. Eur J Cancer 2008; 44: 954-62.

17. McGrath PJ, Johnson G, Goodman JT, Schillinger J, Dunn J, Chapman JA. CHEOPS: A behavioral scale for rating postoperative pain in children. In: Advances in Pain Research and Therapy. Edited by Fields HL, Dubner R, Cervero F: New York, Raven Press. 1985, pp 395-402.

18. Urban MK, Ya Deau JT, Wukovits B, Lipnitsky JY. Ketamine as an adjunct to postoperative pain management in opioid tolerant patients after spinal fusions: a prospective randomized trial. HSS J 2008; 4: 62-5.

19. Adriaenssens G, Vermeyen KM, Hoffmann VL, Mertens E, Adriaensen HF. Postoperative analgesia with i.v. patient-controlled morphine: effect of adding ketamine. Br J Anaesth 1999; 83: 393-6.

20. Yapici D, Atici S, Alic M, Ayan E, Koksel O. Morphine added to local anaesthetic improves epidural analgesia in minimally invasive Nuss operation for pectus excavatum. Br J Anaesth 2008; 100: 280.

21. Rapp SE, Egan KJ, Ross BK, Wild LM, Terman GW, Ching JM. A multidimensional comparison of morphine and hydromorphone patient-controlled analgesia. Anesth Analg 1996; 82: 1043-8.

22. Chang AK, Bijur PE, Meyer RH, Kenny MK, Solorzano C, Gallagher EJ. Safety and efficacy of hydromorphone as an analgesic alternative to morphine in acute pain: a randomized clinical trial. Ann Emerg Med 2006; 48: 164-72.

23. Visser E, Schug SA. The role of ketamine in pain management. Biomed Pharmacother 2006; 60: 341-8.

24. Laulin JP, Maurette P, Corcuff JB, Rivat C, Chauvin M, Simonnet G. The role of ketamine in preventing fentanyl-induced hyperalgesia and subsequent acute morphine tolerance. Anesth Analg 2002; 94: 1263-9.

25. Javery KB, Ussery TW, Steger HG, Colclough GW. Comparison of morphine and morphine with ketamine for postoperative analgesia. Can J Anaesth 1996; 43: 212-5.

26. Murdoch CJ, Crooks BA, Miller CD. Effect of the addition of ketamine to morphine in patient-controlled analgesia. Anaesthesia 2002; 57: 484-8.

27. Good P, Tullio F, Jackson K, Goodchild C, Ashby M. Prospective audit of short-term concurrent ketamine, opioid and antiinflammatory ('triple-agent') therapy for episodes of acute on chronic pain. Intern Med J 2005; 35: 39-44. 